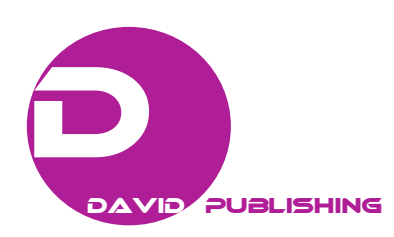

\title{
Technology Innovation in Digital Architectural
}

\section{Processes}

\author{
Consiglia Mocerino \\ Already contract professor in the Faculty of Architecture, Sapienza University of Rome-Miur, Rome, Italy
}

\begin{abstract}
In the new architectural configurations, energy efficiency and savings, are shown mainly by technological development, in the growing field of IT (Information Technology), integrated into the new design concept with intelligent efficiency. The objective is to adopt innovative digital technological systems, with intelligent materials that interact in the new design process and product with the computational designer for buildings which meet the needs of users and optimize efficient spaces. Innovation and energy technology are sharper focus, in tall buildings, office buildings, commercial buildings, hospitals, etc. with adoption of high-performance sensitive technological systems. The methodology is to install efficient buildings, systems with innovative digital devices that interface with the user and the central control system of building automation through Z-wave wireless networks and sensors of BIoT (Building the Internet of Things). So deep energy strategies with flexible and coordinated integrated management for climate control, distribution of electricity from renewable sources, for high-performance digital sensitive architectures, also as a response to climate change at COP 21 in Paris. Thus reducing costs with self-management of smartphones, tablets, and engineering of sustainable materials, nanostructured, to increase thermal insulation performance, mechanical, energy sensitive develops contextualized in the redevelopment of the building.
\end{abstract}

Key words: Architecture, energy, technology, intelligence, material, robotic.

\section{Introduction}

Coworking, open space, fab lab, offices, open meetings, conference room, terms of greater spread that indicate different types of space in which to highlight the most sophisticated of information technology performance, concept launched by the Harvard Business Review to distinguish virtual systems management, automation and physical components (hardware) by software operating systems. Both information technology tools that implement intelligent energy management within a large organization, company or university in which man improves his working life and quality of life. In fact, data processing increased by the development of open source projects, in fields ranging from the industrial, manufacturing, commercial space planning to those environments, training area, residential, etc. become a

Corresponding author: Consiglia Mocerino, Arch. Ph.D., research fields: technological innovation, sustainable and intelligent systems, requalification of buildings and renewable energy. benchmark in the new wealth model, socio/cultural and productive. This stressed the innovative approach for the revival of energy technology, the sustainable growth of the construction and upgrading of the construction industry with reduction of $\mathrm{CO}_{2}$, as in the prospects of the COP 21 in Paris. For this purpose, there are many political strategies aimed at increasing the use of clean and renewable technologies, as reported in the IEA (International Energy Agency) Energy Technology Perspectives model (Fig.1), which would refer you to a pollution reduction even with smart manufacturing and rationalization of resources in the green economy strategies and energy intensive.

Objectives of improving the quality of life and new labor performance are also facilitated by new processes ICT (Information and Communication Technologies) and use of renewable energy resources, which is transformed into that business intelligence, through the intelligent efficiency. In it occurs the energy decentralized convergence GD (Distributed 


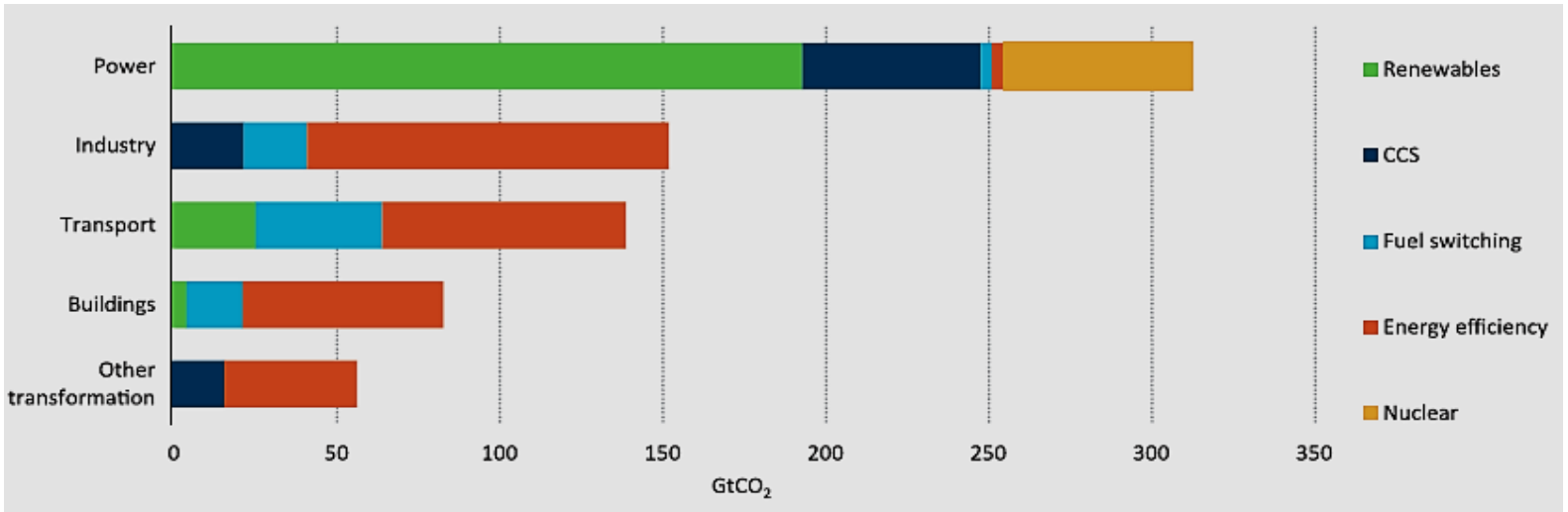

Fig. 1 Cumulative $\mathrm{CO}_{2}$ reductions by industry and technology in the 2DS (2 Degrees Celsius Scenario) 2050.

Source: Ref. [1].

Generation), the IT (Information Technology) world with Cyber-Physical Systems of BIoT (Building the Internet of Things) embedded devices, which indicate the sustainable model of lean manufacturing. It achieves immediate results in production and decision-making level, depending on the rapid transmission data with all the advantages for the best building automation management and for the energy with the launch of building automation in information driver. The methods aim the adoption and application in integrated design, for IS (Information Systems or Services), for data management, computers and MIS (Management Information Services) in a network of intelligent building systems and technological innovation networks. In fact, the innovation of IT, according to US economist theories Skip Laitner [2], contributes to a new dynamic and holistic way of thinking and doing system, overcoming the conception of improvement in only devices. Even J. Rifkin believes that we are seeing a third revolution which emphasizes the large integrated energy resource in both commercial buildings, campuses, etc. In fact, the computer improves product and systems information, with benefits of quality management and control of consumption even with the "pay by use" in the cloud manufacturing of sustainable buildings. So construction of efficient buildings, with compactness criteria, guidance, flexibility, in which the spaces are characterized by ICT integration, contributes to the reduction of environmental loads, reducing energy consumption, technological and architectural quality. reduction of environmental loads, reducing energy consumption.

\section{Methods of the New Construction Process with Intelligent Systems}

Intelligent systems, innovative technologies, new materials with monitoring indicators, for the verification of compliance with quality requirements and design quantities, together with the instruments of control of compliance with the requirements, represent the main process for the construction of sustainable buildings . It is applied throughout the design, construction and operation phases.

With the new information technologies, we are witnessing a transformation of these processes is that project construction, which states the adoption of the digital fabrication technology as drivers of construction with BIM (Building Information Modeling) design.

The new methodologies link, through construction and also 3D high-performance printers, to a more standardized production, with advantages of greater quality control. In fact, even with the branch technology innovation robot machines, they launch on the construction market, the realization multi-storey houses, with multi-functional nano materials, innovative and adaptive. For the materials, from 
nanostructured carbon fiber, the aim is to dwarf cellulose for the reinforcement of nanoresine in 3D printing, according dell'ORNL (Oak Ridge National Laboratory) searches. ${ }^{1}$ They are integrated into the new construction practices and design complexity of digital parametric modeling (BIM), in which the architectural geometric shapes are configured in innovative design, also aimed at the needs of thermal comfort, thermo-fluido-dynamic, lightness, dynamism, brightness, visual, for energy efficiency and sustainability. The architectural envelopes become sensitive through new design and construction methods, contributing to quality of life and results of new habitat daily use of each user performance. In fact, to an autonomous and flexible management, user friendly, to interface with the devices integrated into the building management services, and BEMS (Building Energy Management System), systems BA (Building Automation), it collaborates with the architectural form energetically intelligent components and materials. For example between the high-performance envelope, the relevant contextual thermofluidodynamic aspects, and the requirements of class, are those who have flow wrap exchange with the built and the external environment, with incidence of the solar factor, radiative exchanges and action of the winds. To optimize of the results, the tools for monitoring and tracking, through the integration of computational and numerical control devices software, can provide the most effective and dependable data for thermal comfort in confined spaces, both for new buildings and for those existing, with the optical quality certification. In the latter, it is preferred by deep energy strategies achieving energy savings (30\%) with the revaluation of the value of the building and use of nanowire materials, wireless sensors, fiber optic broadband and photonic crystal CFP (Photonic Crystal Fiber) of microstructured MOF (Metal Organic Frameworks). With a focus on "high-temperature superconductors eco-friendly",

\footnotetext{
${ }^{1}$ https://www.ornl.gov/science-area/advanced-.
}

intermediate band solar cells IBV (Intermediate Band Photovoltaic), from research on materials and EU energy efficiency [3]. The FEM (Finite Element Method) is advantageous for the adaptability of the complex structure with holes, the absence of symmetry and high refractive index, with wide use in concentrated photovoltaic glass electro/photo/thermochromic, etc. The new envelopes with parametric design and digital technology systems adoptions are at the forefront, for the rationalization of energy resources with zero environmental impact. In fact, the regulatory objectives and world and European research, including the European Directive 2010/31/EU on the EPBD (Energy Performance of Buildings Directive), link to nearly zero- energy buildings by 2021 [4], such as Directive 2012/27/EU on energy efficiency.

The performance of robotics contributes to the realization of the envelopes, as instruments of control of the entire building process, with a variety of intelligent systems, including the KNX (Konnex), ${ }^{2}$ launching the best technological devices all over the world, through Expo, fairs between which the Frankfurt light + building 2016, etc. They optimize the building with several intelligent and efficiently functions, working especially to the sensibility of architectural envelopes, through the control of all web services, with Building Automation System integrator in BIoT, with sensors connected through wireless networks to HVAC systems, electrical for the lighting, etc. So energy management integrated up to the energy supply, security of access and the safety with CIB (Computer Integrated Building) integrated cloud computing. The envelopes affect the exchange of flows between inside/outside, as a function of all the conditions, for environments optimized both from the point of view of thermal insulation, and climate weather factors for which they configure with requirements of beauty and sensitive approach in

${ }^{2}$ KNX-Journal 1/2016, www.knx.org, Simple Connection of Intelligent Systems by KNX IoT. 
synergy with intelligence, computational, perceptual, sensory projected on energy saving, efficiency in smart and resilient cities and environmentally sustainable.

\section{The Digital Envelope Architectural Process and BIoT}

Excellent adaptive and innovative component materials work in MEP (Mechanical, Electrical and Plumbing) systems, to increase the Building Automation System [5] of the buildings. In fact, worldwide we see the innovation in the ICT System phenomenon, technology with access to real-time communication through computer networks and which integrates the subsystem IT. So the architectural envelopes are integrated in the environment/land and landscape, through connections to structures or intelligent infrastructure (transport, bridges, dams, tunnels, etc.) with always-on sensors and smart networking, interfacing, in synergy with web services, energy systems, communications technologies with IoT (Internet of Things). In Italy, a digital automated system with ABB (Asea Brown Boveri) IoT technologies and controls the lowering and raising (by up to three meters of the tide) the dam built in the lagoon of Venice, according to Mo.SE (Experimental Electromechanical Module) project, whose 78 gates are hinged on the seabed, in the vicinity of the three inlets. In Rome, the metro B1 as in the bridge Pont de la Poya in Fribourg, Switzerland, for the purpose of green mobility and safety, WSN (Wireless Sensor Network) sensors for monitoring, long-term, structural behavior (EU-CENSIS Project) have been installed. Through these digital applications, also the performance of buildings, in different building types and intended use, they become sensitive, growing along with the innovations of the digital MEP systems. As a result, there has been a simultaneous phenomenon, in this 21 st century, the transformation of the cities that most sensoriate, with database and real-time transmission, becomes smart and resilient, with distributed intelligence. In it, the smartphone apps become between client servers and servers over wireless networks, and transmit indexes to avoid air and noise pollution, alternative routes to heat islands, etc.

Smart sensors are identified and installed at strategic points of the city to monitor, controlling and transmitting data to citizens on mobility. The temperature, and the rate of pollution increase the general government projects such as the Array of Things in Boston and others. Even toward the smart dust, cities respond to reduced accessibility through data information for car sharing, parking, intermodal, logistics management of urban spaces, and green mobility with digital control and monitoring. In these IT contexts, daily activities are planned with social media, instant communications interacting with a network of networks and sensors in a new massive urbanization process. ${ }^{3}$ The computer systems are connected to coworking spaces, workspace, residential, offices, fab labs, hospitals, intelligent buildings with sensitive envelopes and components "appliance in the wall", electrochromic glazing (EC) powered by PV (photovoltaic) (Fig. 2) Low-E film, etc., with technological requirements, environmental and construction.

In fact, for these three basic classes of requirements, it is essential to respond to the satisfaction of needs above all safety, health, usability, appearance, management, integration and protection of the environment of the building system, according to the Italian UNI 8289. But between the Italian technical regulations, the performance of the building with energy requirements for HVAC systems, UNI/TS 11300 , correspond in part to the housing needs. The rules follow a trend of technological innovations, but also of new design processes with satisfaction of user requirements overcoming the constraints that the environment poses to built, with the development of digital technologies.

\footnotetext{
${ }^{3}$ www.unhabitat.org.
} 


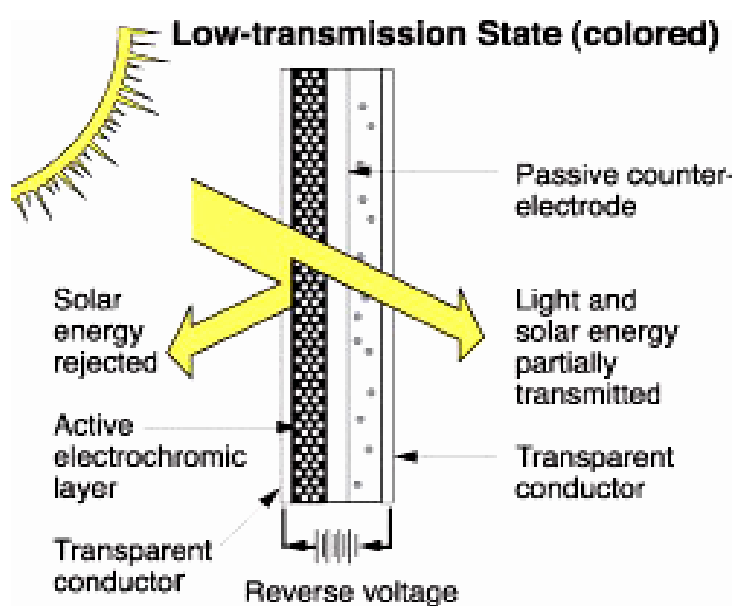

Fig. 2 Electrochromic window with colored films. Source: Ref. [6].

They are aimed at building automation, where the user manages all systems in the building, user friendly manner and pay by use. In fact with IT improve the choices for the new automated management for energy purposes in which priority must be given constructive and innovative materials technologies for external insulation, with low indices of thermal transmittance $U\left(\mathrm{~W} / \mathrm{m}^{2} \mathrm{~K}\right)$, envelope insulation of $S / V$ (ratio of the dispersing surface and the gross volume), with improvement of the thermal resistance of the walls $R \quad\left(\mathrm{~m}^{2} \mathrm{~K} / \mathrm{W}\right)$ and of the materials conductivity $W /(\mathrm{m} \cdot \mathrm{K})$. Through the evolution of wireless, technologies have improved the automation systems of the BAS (Building Automation System), integrated with IoT and $\mathrm{M}_{2} \mathrm{M}^{2}$ (Machine to Machine) protocol LPWA technologies-Low Power Area Wide (Lora, SigFox, Qowisio, etc.), which connect to broad spectrum and energy consumption, while having a simple network structure.

Technologies for integrated building management connect to these wireless networks with results of improved data transmission, real-time, for the purpose of monitoring and consumption with smart data logger, control and energy saving, with reduced energy costs by up to $20 \%$. According to Article 8 of the European Directive 2010/31/EU-EPBD, it establishes the installation of automation systems in buildings. Are the types of systems BEMS and BMS (Building
Management System) with types of plants BACS (Building Automation and Control System)/HBES (Home and Building Electronic System) for heating, cooling, ventilation, air conditioning (HVAC), DHW (Domestic Hot Water) production, lighting, control of solar shading.

Instead, types of plants TBM (Technical Building Management) are adopted for the centralized system and building control, diagnostics and detection of consumption data for the improvement of automation parameters. Both of these two types of plant are targeting energy efficiency, comfort and security of the building. They are also displayed and controlled for the electrical system, fire fighting, security of accesses, acoustic, for the behavior of users outdoor/indoor, the safety and security, for monitoring the integrity of the building, etc., on the programmed settings that the user runs through apps on smartphones, tablet PCs, cell phones, touch screen devices, wearable device, or fixed devices installed in the building.

The best performance will occur in tertiary, commercial, residential, institutional, hospitality facilities, hospitals, new construction, but also in the building retrofit, with automation that transforms into building the internet of things (Fig. 3).

Moreover, even smart metering is inserted between the optimization objectives of automatic building envelope energy management systems, avoiding peak loads, through visualization of energy consumption and electric control devices connected to those of the monitoring. It finalizes the management to the lower energy consumption water, gas, heat and electricity supplies through an innovative sensors trend, recently also optical and integrated optofluidic, actuators, digitization and automation of counters. They have a display and intelligent measuring instruments. In fact, the transmission system takes place on three key platforms of cloud services: managing the various processes in the building, telecommunications equipment, Z-wave wireless sensors. 
In fact, through cloud and wireless technologies, automated devices are to activate plant of BAS management (lighting, HVAC, etc.). The building of building automation platform integrated by Internet of Things.

Thus in large buildings for offices and work environments, you can program the temperature of the air conditioner, lighting, video surveillance, etc. in function of the amount of hours of daytime work, the users' presences with switching on and off, at the end of the activities and monitoring the relative consumption.

Sustainable building, The Edge, $40,000 \mathrm{~m}^{2}$ of office space on 15 floors, including the newly built Tall Building 2014, located in the Zuidas District in Amsterdam, in Europe, is a project of the architects Lee Polisano en Ron Bakker van PLP/Architecture-Oever Zaaijer, for the financial company Deloitte and law firm AKD (Fig. 4). The facilities are concrete slabs with large span, steel and glass curtain walls.

The atrium is on the north by thick glass (Fig. 5), also for acoustic protection of office areas, with small openings designed to shading and thermal mass, to the west with natural ventilation by opening panels. 4,100 square meters of $\mathrm{PV}$ is installed on the roof, energy-related University of Amsterdam and solar panels in south facade, on areas no windows of the offices. It is the first building in the world in which PoE (Power over Ethernet) is realized (Fig. 6) provided by Philips, in which a single cable, installed in false ceilings, the digital network, feeds the data transmitted from 30,000 sensors for LED (Light-Emitting Diode) lighting, the degree of humidity, the temperature, users movement, ventilation, computer data and other devices building. Excellent integration for the facility manager that controls both energy models, that employments for an integrated energy management and labor. So the building is constructed of solar paths, with energy efficiency targets and intelligence efficiency. In fact, the adoption of "Technology Turns" PoE achieved an optimization of $20 \%$ of the space, for flexible workstations, parking, service teams, lighting and temperature managed by users with apps on smartphones or laptop, with high environmental comfort and wellness indoor standards, affecting mainly on productivity and profitability.

The horseshoe-shaped plan is articulated with an atrium-core buffer with offices, very enlightened with air conditioning, in excess, gathering in the atrium, through an exchanger, at the top, it is reused in the

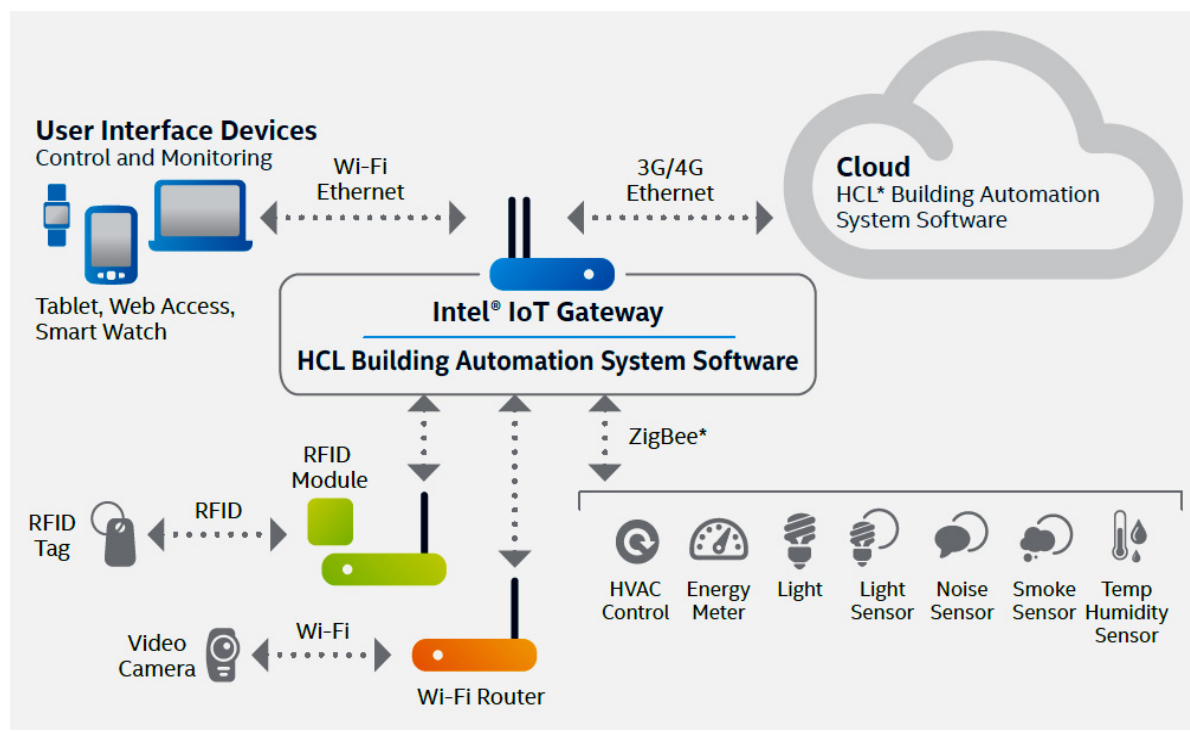

Fig. 3 Building Automation System enable by Internet of Things.

Source: Ref. [7]. 


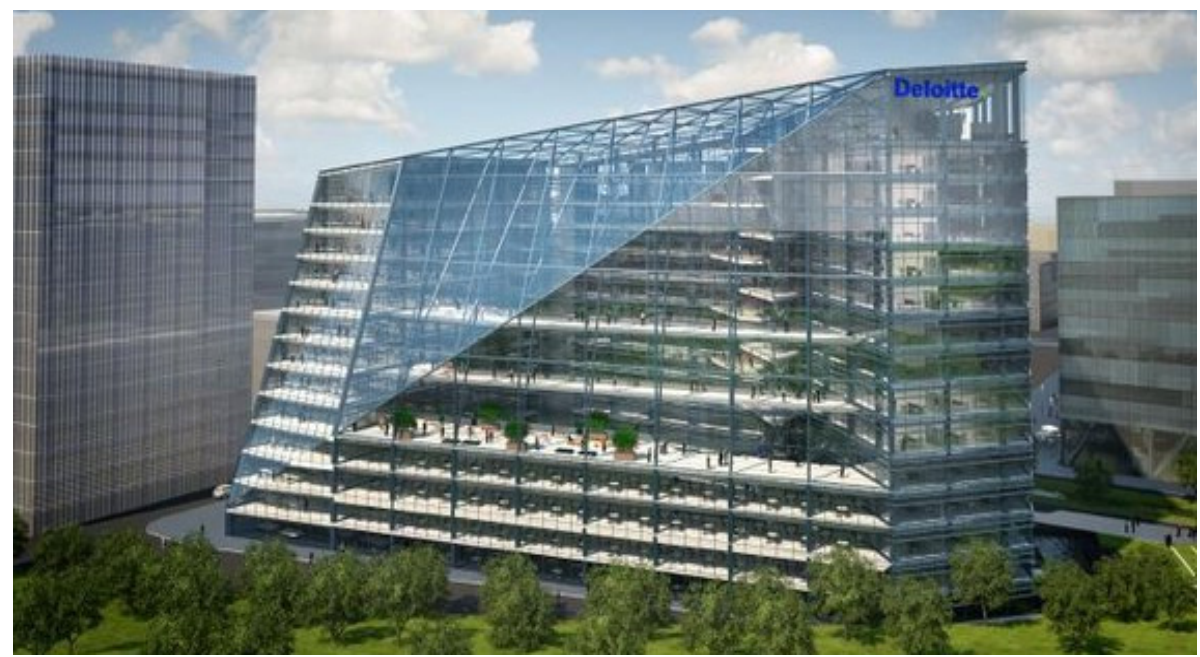

Fig. 4 The Edge-Amsterdam. View to north.

Source: Ref. [8].

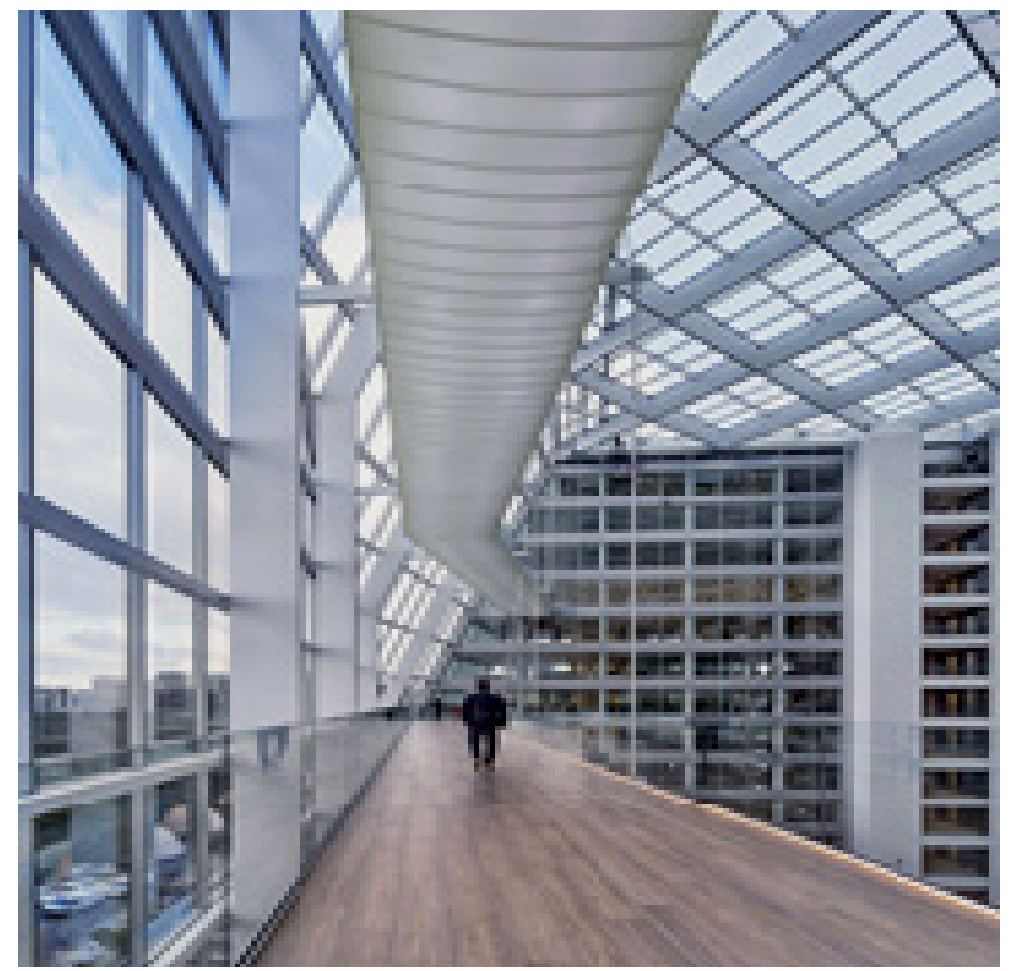

Fig. 5 The Edge. Atrium on the north.

Source: Ref. [9].

same offices and again in the atrium. Energy strategies indicate an LED lighting system powered by Ethernet and $100 \%$ IP based, connected to 6,000 devices with "coded-light" of better performance than WiFi. They use $3.9 \mathrm{~W} / \mathrm{m}^{2}$ compared to $8 \mathrm{~W} / \mathrm{m}^{2}$ and distribute than standard 300 Lux 500 Lux, with excellent energy savings and a total of $40 \%$ energy savings and $80 \%$ light, $30 \%$ of electricity consumption and $70 \%$ use electrical reduction, in less.

These last two are powered by geothermal energy of two wells (depth $130 \mathrm{~m}$ ) of thermal energy accumulation as a function of hot or cold climate. A pump system connected to them is powered by solar energy. The EM (Energy Management) through the BMS, indicates a remote insight anonymous users, with control of energy consumption, management and 


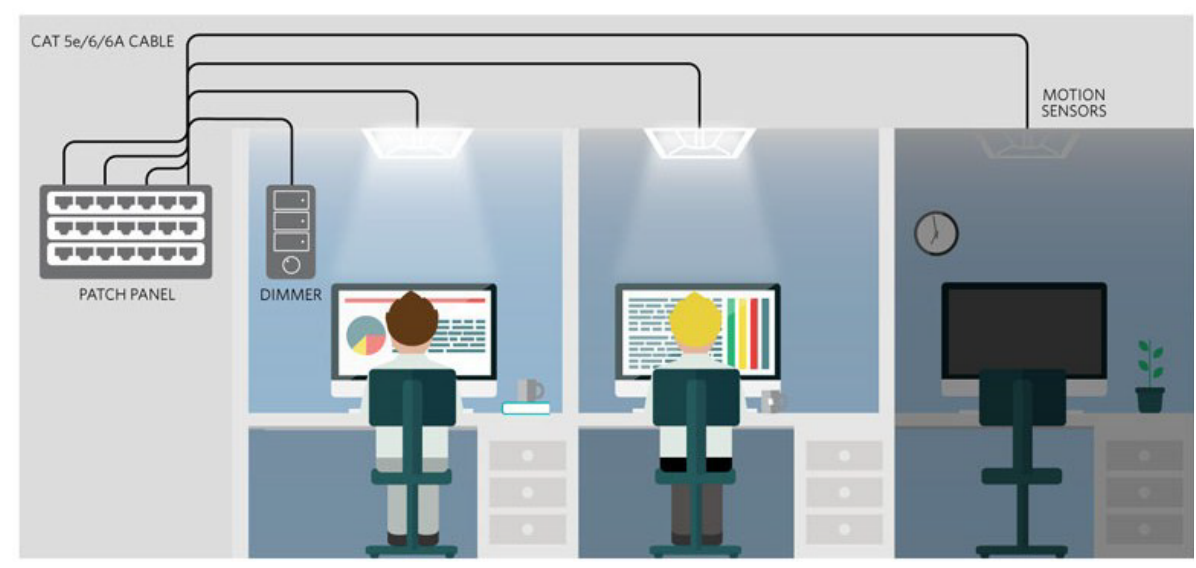

Fig. 6 PoE-LED lighting.

Source: Ref. [10].

even activation of the user flow for the table, for saving food waste, environments not used to avoid the daily cleaning, etc. The rainwater, recovered by a collection system on the roof that pours into a concrete tank, in the back of the garage, feeds the irrigation of indoor/outdoor vegetation and is reused for water and sanitary system.

A robot device checks if there are facilities anomalies or false alarms. Compared to a normal building, it is expected that, after 10 years, it will save about 42 million $\mathrm{kg}$ of $\mathrm{CO}_{2}$ and it has been certified by the Breem NL Outstanding Rating Quality, Sustainable Leadership Awards.

\section{Conclusions}

The business intelligence is the excellence of the result of new ICT processes, into which renewable resources are used, the new working performance with the help of Intelligence Efficiency. The goals are certainly aimed at improving the quality of life of every person who enjoys for enclosed spaces (housing and work) and those opened in the context. So become benckmark the continued evolution of both the spatial configuration of the building systems, technological and plan engineering, to meet and comply with the needs of users, social and environmental. For this purpose, are indispensable for the design, morphological and climatic aspects, the orientation, the altitude, type of vegetation,etc. in order to integrate the energy/system choices, for energy efficiency. In the buildings, the user interacts, through intelligent systems, with interfaces, in a user friendly mode, to optimize the internal management system of the building with the innovations of ICT, while the envelope also interacts with the built and the environment [11]. So, in terms of comfort, environmental well-being and quality of life indoors, in new buildings and those for the redevelopment [12], it aims at new process models and products finalized at high performance of the envelopes that become sensitive, efficient and that point to sustainability.

\section{References}

[1] IEA. 2015. Energy Technology Perspectives 2015. Executive summary. Mobilising Innovation to Accelerate Climate Action.

[2] Laitner, J. A. S. 2013. Linking Energy Efficiency to Economic Productivity: Recommendations for Improving the Robustness of the U.S. Economy. Washington, DC: American Council for an Energy-Efficient Economy.

[3] Europe Commission. 2016. Eco-friendly High-Temperature Superconductors. A project of Europe Commission. Accessed April 15, 2016. http://cordis.europa.eu/result/rcn/92753_en.html.

[4] D'Agostino, D., Zangheri, P., Cuniberti, B., Paci, D., and Bertoldi, P. 2016. Synthesis Report on the National Plans for Nearly Zero Energy Buildings (NZEBs): Progress of Member States towards NZEBs. Publications Office of the European Union. Accessed June 21, 2016. https://ec.europa.eu/jrc/en/publication/eur-scientific-and-t 
echnical-research-reports/synthesis-report-national-plansnearly-zero-energy-buildings-nzebs-progress-member-sta tes.

[5] Chiesa, G. 2015. Paradigmi, Tecnologie ed ere Digitali. Il dato come Parametro di Innovazione di Architettura. Torino: Accademia University Press. (in Italian)

[6] EWC (Efficient Windows Collaborative). n.d. "Gasochromic Windows.” EWC. Accessed May 11, 2016. http://www.commercialwindows.org/gasochromic.php.

[7] Intel Corporation. n.d. Intel Affordable Building Automation System Enabled by IoT-Intel. Accessed May 3, 2016. www.intel.com/.../internet-of-things/blueprints/ iot-building-auto....

[8] TCS. 2016. The Edge Amsterdam. Accessed May 12, 2016. http://www.thermalcomfortsystems.nl/referenties/ kantoor/the.edgeamsterdam.

[9] PLP Architecture. n.d. The Edge Amsterdam, The Netherlands. Accessed May 12, 2016. http://www.plparchitecture.com/the-edge.html.
[10] In Electronics. 2015. Technology Power-over-Ethernet (PoE) for the Lighting Industry. Accessed May 12, 2016. http://blog.elettronicain.it/2015/07/03/.the-techno logy.-power-overethernet-poe-per-il-settore-dellilluminaz ione.

[11] Mocerino, C. 2016. "Efficiency and Intelligence in New and Existing Offices." In Proceedings of the 9th International Conference Improving Energy Efficiency in Commercial Buildings and Smart Communities-IEECB\&SC'16, (Frankfurt, Germany) by Bertoldi, P. Accessed August 18, 2016. http://publications.jrc.ec.europa.eu/repository/bitstream/J RC102161/jrc102161_ieecb-sc-16-3.pdf.

[12] Mocerino, C. 2015. "Modello Edilizio nell' Innovazione di Processo Progettuale per il Recupero e la Riqualificazione Dell'Edilizia Terziaria. Linee Guida Prestazionali." PhD thesis, Sapienza University of Rome. Accessed June 30, 2016. http://padis.uniroma1.it/handle/ 10805/2766. File: Tesi DdR. C.Mocerino XXVI ciclo.pdf. 